DOI: http://dx.doi.org/10.33846/ghs5407

\title{
Hubungan Tingkat Pengetahuan dan Sikap Pengawas Menelan Obat (PMO) Dengan Kepatuhan Pasien TB Paru di Wilayah Kerja Puskesmas Perawatan Kairatu
}

\author{
Wiwi Rumaolat (koresponden) \\ (IImu Kesehatan Masyarakat; STIKes Maluku Husada; wiwi.rumaolat@gmail.com) \\ Maryam Lihi \\ (IImu Kesehatan Masyarakat; STIKes Maluku Husada: yamsee_qweenle@gmail.com) \\ Siti Nur Atika Rengur \\ (IImu Kesehatan Masyarakat; STIKes Maluku Husada; sitinuratikarengur@gmail.com) \\ Sri Mulyati Tunny \\ (IImu Kesehatan Masyarakat; STIKes Maluku Husada; srimulyanitunny@gmail.com)
}

\begin{abstract}
ABSTRAK
Tuberkulosis (TB) Paru sebagai suatu problema kesehatan masyarakat yang sangat penting dan serius untuk ditangani terutama di provinsi maluku yang dari tahun ke tahunnya selalu mengalami peningkatan angka penderita TB Paru. Tujuan penelitian ini untuk mengetahui hubungan tingkat pengetahuan dan sikap PMO dengan kepatuhan pasien TB Paru di Wilayah Kerja Puskesmas Perawatan Kairatu. Desain penelitian ini bersifat deskriktif analitik dengan pendekatan cross sectional. Hasil uji menunjukan adanya hubungan tingkat pengetahuan dan sikap pengawas menelan obat dengan kepatuhan pasien tb paru di wilayah kerja puskesmas perawatan kairatu. ini diperkuat dengan hasil uji statistik chi-square dimana koefisien phi dengan nilai $p$-value $=0.001(<0,05)$.
\end{abstract}

Kata kunci: pengetahuan; sikap; kepatuhan; tuberkulosis paru

\section{PENDAHULUAN}

\section{Latar Belakang}

Tuberkulosis Paru (TB Paru) merupakan penyakit yang menjadi perhatian global. Dengan berbagai upaya pengendalian yang di lakukan, insiden dan kematian akibat TB Paru telah menurun, namun tb paru di perkirakan masih menyerang 9,6 juta orang yang menyebapkan 1,2 juta kematian pada tahun 2014. Indinesia merupakan salah satu negara dengan penderitaan TB Paru terbanyak setelah indian yaitu $10 \%$ dari seluruh penderita di dunia. ${ }^{(1)}$

TB Paru adalah suatu penyakit menular yang disebabkan oleh kuman Mycobacterium tuberculosis. Sumber penularan yaitu penderita TB Paru BTA (bacteri tahan asam) positif melalui perciksn renik dahak yang dikeluarkannay. TB Paru dengan BTA negatif juga masih memilki kemungkinan menularakan penyakit TB Paru meskipun dengan tingkat penularan yang kecil. Berdasarkan studi pendahuluan di Puskesmas Perawatan Kairatu didapatkan data bahwa prevalensi penderita TB Paru pada tahun 2017 sejumlah 17 orang (24\%), tahun 2018 sejumlah 25 orang (35\%), dan meningkat pada tahun 2019 sejumlah 30 orang (41\%). (2)

Keberadaan PMO dalam masa pengobatan penderita TB Paru sangat membantu, karena ketidakpatuhan penderita dalam berobat disebabkan oleh tidak adanya konsistensi dari penderita dalam mengambil obat, kontrol kembali ke puskesmas, serta mengkonsumsi obat selama 6 bulan. Sehingga PMO berperan sebagai pengingat pada penderita untuk kembali mengambil obat dan mengontrol kesehatan ke tempat pelayanan kesehatan terdekat dan berperan juga sebagai motivator kepada penderita dalam menjalani pengobatan. Apabila penderita tersebut tidak patuh dalam proses pengobatan, maka tingkat keberhasilan pengobatan penderita akan semakin menurun. Saat mengkonsumsi obat beberapa penderita TB Paru akan mengalami efek samping dari konsumsi Obat Anti TB (OAT), seperti: demam, gatal-gatal, nafsu makan menurun, mual, dan perasaan tidak enak yang bisa menyebabkan penderita untuk berhenti mengkonsumsi OAT. Peran PMO dalam hal ini adalah memotivasi penderita agar penderita tetap mengkonsumsi OAT sesuai anjuran petugas kesehatan, dengan tujuan mencegah penderita memutuskan masa pengobatan dan mencegah resistensi obat. Pengetahuan serta sikap PMO merupakan faktor resiko terjadinya ketidak patuhan penderita TB Paru dalam meminum obat, PMO dengan pengetahuan dan sikap yang kurang menyebapkan dua kali lebih beresiko terhadap ketidak patuhan penderita TB Paru dalam meminum obat.(Permenkes RI 67 tahun 2016). ${ }^{(3),(4)}$

Salah satu penyebab kegagalan tersebut adalah perilaku tidak patuh penderita terhadap pengobatan. Kepatuhan dalam minum obat sangat penting untuk menghindari MDR sehingga 
diperlukan Pengawas Minum Obat (PMO). PMO bertugas mengawasi dan mendampingi pasien sampai tuntas pengobatan (sembuh) agar terhindar dari kejadian drop out yang mengarah pada kegagalan seperti resisiten, kambuh bahkan kematian. Anggota keluarga atau petugas kesehatan yang dekat dengan pasien dapat menjadi PMO. ${ }^{(5)}$

Puskesmas perawatan Kairatu sebagai salah satu wilayah dengan jumlah penderita TB paru 30 orang dan jumlah pengobatan 25 penderita. Berdasarkan studi pendahuluan yang dilakukan oleh peneliti terdapat penderita resisiten pengobatan (MDR-TB) sebanyak 2 orang. Fakta ini mengindikasikan adanya kegagalan pengobatan TB.

\section{Tujuan Penelitian}

Tujuan penelitian ini untuk mengetahui hubungan tingkat pengetahuan dan sikap PMO dengan kepatuhan pasien TB Paru di wilayah kerja puskesmas perawatan kairatu.

\section{METODE}

Desain yang digunakan dalam penelitian ini adalah deskriptif analitik, penelitian diarahkan untuk menghubungkan antara tingkat pengetahuan dan sikap PMO dengan kepatuhan penderita TB Paru dalam berobat di Wilayah Puskesmas Perawatan Kairatu. Metode penelitian yang digunakan adalah metode survey dengan pendekatan tekhnis langsung karena meneliti variabel penelitian pada saat yang sama yaitu dimana pengukuran subyek hanya satu kali saja dan dilakukan terhadap variabel pada saat. ${ }^{(6)}$

\section{HASIL}

\section{Karakteristik Responden}

$\underline{\text { Usia }}$

Tabel 1. Distribusi responden berdasarkan Usia PMO Penderita TB Paru di Wilayah Kerja Puskesmas Kairatu Tahun 2019

\begin{tabular}{|c|l|c|c|}
\hline No & Usia & $\mathrm{n}$ & $(\%)$ \\
\hline 1 & Remaja akhir 17-25 tahun & 5 & 16.7 \\
\hline 2 & Dewasa awal 26-35 tahun & 12 & 40.0 \\
\hline 3 & Dewasa akhir 36-45 tahun & 8 & 26.7 \\
\hline 4 & Lansia awal 46-55 tahun & 4 & 13.3 \\
\hline 5 & Lansia Akhir 56-65 tahun & 1 & 3.3 \\
\hline \multicolumn{2}{|c|}{ Total } & 30 & 100.0 \\
\hline
\end{tabular}

Tabel 1 menunjukkan bahwa dari 30 responden yang menjadi sampel, responden yang paling banyak adalah usia dewasa awal yaitu 12 orang (40.0\%).

Jenis kelamin

Tabel 2. Distribusi Responden berdasarkan Jenis Kelamin PMO Penderita TB Paru di Wilayah Kerja Puskesmas Kairatu Tahun 2019

\begin{tabular}{|c|c|c|c|}
\hline No & Jenis Kelamin & $\mathrm{n}$ & $(\%)$ \\
\hline 1 & Laki-laki & 11 & 36.7 \\
\hline 2 & Perempuan & 19 & 63.3 \\
\hline \multicolumn{2}{|c|}{ Total } & 30 & 100.0 \\
\hline
\end{tabular}

Tabel 2 menunjukkan bahwa responden lebih banyak perempuan 19 responden (63.3\%).

\section{Pendidikan terakhir}

Tabel 3 dari hasil uarian diatas pendidikan terakhir menunjukkan bahwa dari 30 responden yang menjadi sampel, responden yang paling banyak berpendidikan terakhir adalah SMA yaitu 15 orang $(50.0 \%)$. 
Tabel 3. Distribusi Responden berdasarkan Pendidikan Terakhir PMO Penderita TB Paru di Wilayah Kerja Puskesmas Kairatu Tahun 2019

\begin{tabular}{|c|c|c|c|}
\hline No & Pendidikan terakhir & $\mathrm{n}$ & $(\%)$ \\
\hline 1 & SD & 2 & 6.7 \\
\hline 2 & SMP & 5 & 16.7 \\
\hline 3 & SMA & 15 & 50.0 \\
\hline 4 & D3/D4/S1 & 8 & 26.7 \\
\hline \multicolumn{2}{|c|}{ Total } & 30 & 100.0 \\
\hline
\end{tabular}

Pekerjaan

Tabel 4. Distribusi Responden Berdasarkan Pekerjaan PMO Penderita TB Paru Di Wilayah Kerja Puskesmas Kairatu Tahun 2019

\begin{tabular}{|c|c|c|c|}
\hline No & Pekerjaan & $\mathrm{n}$ & $(\%)$ \\
\hline 1 & Tidak Bekerja & 5 & 16.7 \\
\hline 2 & Petani & 2 & 6.7 \\
\hline 3 & IRT & 11 & 36.7 \\
\hline 4 & PNS & 6 & 20.0 \\
\hline 5 & Nelayan & 2 & 6.7 \\
\hline 6 & Wirausaha & 4 & 13.3 \\
\hline \multicolumn{2}{|c|}{} \\
\hline
\end{tabular}

Tabel 4 menunjukkan bahwa dari 30 responden yang menjadi sampel, responden yang paling banyak berkerja adalah sebagai IRT yaitu 11 orang (36.7\%).

\section{Analisa Univariat}

Pengetahuan

Tabel 5. Distribusi Responden Berdasarkan Pengetahuan PMO Penderita TB Paru Di Wilayah Kerja Puskesmas Kairatu Tahun 2019

\begin{tabular}{|c|c|c|c|}
\hline No & Pengetahuan & $\mathrm{n}$ & $(\%)$ \\
\hline 1 & Baik & 11 & 36.7 \\
\hline 2 & Cukup & 13 & 43.3 \\
\hline 2 & Kurang & 6 & 20 \\
\hline \multicolumn{2}{|c|}{ Total } & 30 & 100 \\
\hline
\end{tabular}

Tabel 5 Untuk variabel pengetahuan menunjukkan bahwa dari 30 responden yang diteliti yang paling banyak ialah responden yang memiliki pengetahuan yang cukup berjulmah berjumlah 13 responden (43.3\%).

\section{$\underline{\text { Sikap }}$}

Tabel 6. Distribusi Responden Berdasarkan Sikap PMO Penderita TB Paru Di Wilayah Kerja Puskesmas Kairatu Tahun 2019

\begin{tabular}{|c|c|c|c|}
\hline No & Tindakan & $\mathrm{n}$ & $(\%)$ \\
\hline 1 & Positif & 25 & 83.3 \\
\hline 2 & Negatif & 5 & 16.7 \\
\hline \multicolumn{2}{|c|}{ Total } & 30 & 100.0 \\
\hline
\end{tabular}

Tabel 6 dari hasil uraian diatas ddiperoleh untuk responden terbanyak ialai yang memiliki sikap positif berjumlah 25 responden (83.3\%). 
Kepatuhan

Tabel 7. Distribusi Responden Berdasarkan Gambaran Kepatuhan Penderita TB Paru Di Wilayah Kerja Puskesmas Kairatu Tahun 2019

\begin{tabular}{|c|c|c|c|}
\hline No & Tindakan & $\mathrm{n}$ & $(\%)$ \\
\hline 1 & Patuh & 27 & 90.0 \\
\hline 2 & Tidak patuh & 3 & 10.0 \\
\hline \multicolumn{2}{|c|}{ Total } & 30 & 100.0 \\
\hline
\end{tabular}

Tabel 7 berdasarkan uraian diatas diperoleh untuk responden yang memiliki sikap patuh penderita tb paru berjumlah 27 responden (90.0\%) sedangkan untuk sikap tidak patuh sebanyak 3 responden (10.0\%).

\section{Analisa Bivariabel}

\section{Hubungan Tingkat Pengetahuan PMO Dengan Kepatuhan Penderita TB Paru Dalam Berobat}

Tabel 8. Hubungan Tingkat Pengetahuan PMO dengan Kepatuhan Penderita TB Paru Di Wilayah Kerja Puskesmas Perawatan Kairatu Tahun 2019

\begin{tabular}{|c|c|c|c|c|c|c|c|}
\hline \multirow{2}{*}{ Pengetahuan } & \multicolumn{4}{|c|}{ Kepatuhan } & \multicolumn{2}{|c|}{ Total } & \multirow{2}{*}{ p.value } \\
\cline { 2 - 6 } & \multicolumn{2}{|c|}{ Patuh } & \multicolumn{2}{c|}{ Tidak Patuh } & \multicolumn{2}{c|}{ Total } & \\
\cline { 2 - 6 } & $\mathrm{n}$ & $\%$ & $\mathrm{n}$ & $\%$ & $\mathrm{n}$ & $\%$ & \\
\hline Baik & 11 & $36.7 \%$ & 0 & $0 \%$ & 11 & $36.7 \%$ & $\mathrm{P}=0.001$ \\
\hline Cukup & 13 & $43.3 \%$ & 0 & $0 \%$ & 11 & $43.3 \%$ & \\
\hline Kurang & 3 & $10.0 \%$ & 3 & $10.0 \%$ & 6 & $20.0 \%$ & \\
\hline Total & 27 & $90.0 \%$ & 3 & $10.0 \%$ & 30 & $100.0 \%$ & \\
\hline
\end{tabular}

Tabel 8 menjelaskan bahwa responden terbanyak adalah responden yang memiliki pengetahuan yang cukup 13 (43.3\%) dengan kategori semua pasien TB Paru patuh dalam meminum obat.

Hubungan sikap PMO dengan kepatuhan penderita TB Paru

Tabel 9. Hubungan Sikap PMO Dengan Kepatuhan Penderita TB Paru Di Wilayah Kerja Puskesmas Perawatan Kairatu Tahun 2019

\begin{tabular}{|c|c|c|c|c|c|c|c|}
\hline \multirow[t]{3}{*}{ Sikap } & \multicolumn{4}{|c|}{ Kepatuhan } & \multirow{2}{*}{\multicolumn{2}{|c|}{ Total }} & \multirow[t]{3}{*}{ p.value } \\
\hline & \multicolumn{2}{|c|}{ Patuh } & \multicolumn{2}{|c|}{ Tidak Patuh } & & & \\
\hline & $n$ & $\%$ & $\mathrm{n}$ & $\%$ & $\mathrm{n}$ & $\%$ & \\
\hline Positif & 25 & $83.3 \%$ & 0 & 0 & 25 & $83.3 \%$ & \\
\hline Negatife & 2 & $6.7 \%$ & 3 & $10.0 \%$ & 5 & $16.7 \%$ & $P=0.001$ \\
\hline Total & 27 & $90.0 \%$ & 3 & $10.0 \%$ & 30 & $100.0 \%$ & \\
\hline
\end{tabular}

Tabel 9 di atas menunjukan bahwa dari 30 responden yang diteliti $25(83.3 \%)$ diantaranya bersikap positif dengan kepatuhan penderita TB Paru sebanyak orang $25(83.3 \%)$ responden juga.

\section{PEMBAHASAN}

\section{Hubungan Pengetahuan PMO dengan Kepatuhan Penderita TB Paru}

Hasil analisis menemukan bahwa adanya hubungan yang signifikan antara pengetahuan PMO dengan kepatuhan penderita TB Paru dalam meminum obat, ini diperkuat dengan hasil uji statistik chi-square dimana koefisien phi dengan nilai $p$-value $=0.001(<0,05)$. Semakin tinggi tingkat pendidikan seseorang, maka orang tersebut akan semakin mudah untuk menerima informasi yang 
secara tidak langsung mempengaruhi tingkat pengetahuannya. Secara tidak langsung sikap seseorang juga dipengaruhi oleh pengetahuan. Jadi dapat disimpulkan bahwa pengetahuan PMO yang berpengetahuan rendah dapat mempengaruhi sikap PMO dan perilaku PMO saat PMO berperan untuk mendampingi penderita TB paru saat dalam masa pengobatan. ${ }^{(7)}$

PMO yang berasal dari anggota keluarga dianggap memiliki peran yang besar dalam meningkatkan kepatuhan pengobatan pasien, misalnya memotivasi pasien dan melakukan pengawasan secara langsung kepada pasien saat berobat, karena keluarga adalah orang yang paling dekat dengan pasien. Hal ini juga berkaitan dengan kedekatan emosional. Apabila pasien tidak patuh terhadap apa yang dianjurkan oleh PMO, PMO bisa dengan langsung menegur pasien tanpa merasa tidak enak. Selain kedekatan emosional, pasien juga tidak merasa berhutang budi dan harus membalas jasa PMO atas bantuan PMO selama masa pengobatan. Peran PMO yang berasal dari anggota keluarga memiliki hubungan dengan angka keberhasilan pengobatan $(p=0,000)$, dan keluarga yang berperan baik sebagai PMO memiliki peluang 20 kali lebih besar terhadap tingkat keberhasilan pengobatan pasien. ${ }^{(8)}$

\section{Hubungan Sikap PMO dengan Kepatuhan Penderita TB Paru}

Hasil analisis menunjukkan bahwa adanya hubungan yang signifikan antara sikap PMO dengan kepatuhan penderita TB Paru, ini diperkuat dengan hasil uji statistik dimana koefisien phi dengan nilai $p$ value $=0.001(<0.05)$.

sikap merupakan hasil dari sebuah pikiran dan akan diaplikasikan menjadi sebuah perilaku atau kesiapan untuk berperilaku. Jadi, pengukuran sikap ini juga mengukur keinginan berperilaku PMO yang masih belum diaplikasikan (tertutup). Misalnya: rencana PMO yang akan tetap memeriksakan kesehatan pasien TB secara rutin agar mencegah kekambuhan. Rencana PMO tersebut sudah termasuk dalam kategori sikap, karena pikiran PMO merespon positif terhadap apa yang diketahuinya dan akan diaplikasikan menjadi sebuah perilaku atau tindakan. (9) Apabila PMO memiliki kinerja yang baik dalam melaksanakan peran dan tugasnya, maka motivasi pasien untuk berobat secara teratur akan semakin dan tinggi, dan berpengaruh positif terhadap tingkat keberhasilan pengobatan pasien juga. (10) Sikap dipengaruhi oleh beberapa hal antara lain pengalaman pribadi, pengaruh orang lain yang dianggap penting, pengaruh kebudayaan, media massa, lembaga pendidikan dan keagamaan, serta faktor emosional. (11) Namun sikap PMO dalam penelitian ini lebih cenderung dipengaruhi oleh pengalaman pribadi. Hal tersebut terbukti dengan beberapa PMO kasus dengan pasien drop out menceritakan bahwa pasien tersebut memilih untuk drop out karena tidak kuat untuk menghadapi efek samping dari konsumsi OAT, lalu memilih untuk mengkonsumsi obat yang diberikan oleh dokter praktik swasta dan apotik. Hal tersebut menggambarkan pentingnya dukungan dan motivasi penuh dari PMO untuk mencegah kejadian drop out. Terbukti juga dengan penelitian yang dilakukan oleh Octovianus, et al., (2015). Penelitian tersebut mendapatkan $p=0,000$, yang berarti bahwa motivasi dari keluarga yang berperan sebagai PMO mempengaruhi kejadian drop out penderita TB paru. ${ }^{(12)}$

\section{KESIMPULAN}

Adanya hubungan antara pengetahuan pengawas menelan obat (PMO) dengan kepatuhan pasien TB Paru di Wilayah Kerja Puskesmas Perawatan Kairatu. Adanya hubungan antara sikap pengawas menelan obat (PMO) dengan kepatuhan pasien TB Paru di Wilayah Kerja Puskesmas Perawatan Kairatu. Adanya hubungan antara pengetahuan dan sikap pengawas menelan obat (PMO) dengan kepatuhan pasien TB Paru di Wilayah Kerja Puskesmas Perawatan Kairatu.

\section{DAFTAR PUSTAKA}

1. Kemenkes, R. I. (2017). Profil Kesehatan Republik Indonesia. Jakarta R. I. (2014). Pedoman Nasional Pengendalian Tuberkulosis. Jakarta.

2. Kurniasih E, Hamidatus D.S. 2017. Hubungan Peran Pengawas Menelan Obat (PMO) dengan Kepatuhan Minum Obat Pasien Tuberculosis Paru di Wilayah Kerja Puskesmas Ngawi. Jurnal Kesehatan Warta Bhakti Husada Mulia. Vol 4, No 2.

3. T.D. Hartanto, L.D. Saraswati, M.S. Adi. 2019. Analisis Spasial Persebaran Kasus Tuberculosis Paru di Kota Semarang Tahun 2018. Jutnal Kesehatan Masyarakat. (e-Journal) Volume 7, Nomor 4 (ISSN: 2356-3346).

4. Astutik, (2013). Data Dan Riset Kesehatan Daerah Dasar : (Riskesdas)

5. Crofton, J. (2007) Tuberculosis Klinis. Edisi ketiga. Jakarta: Widya Medika 
6. Natoatmodjo, (2010). Pendidikan Dan Perilaku Kesehatan. Jakarta PT Rineka Cipta

7. Nazilatul F. 2017. Hubungan Karakteristik Pengawas Menelan Obat terhadap Kepatuhan Berobat Pasien Tuberculosis di Puskesmas Pragaan Tahun 2016. Jurnal Berkala Epidemiologi, Volume 5 Nomor 3, hlm. 338-350.

8. Jufrizal., Hermansyah., Mulyadi. 2016. Peran Keluarga Sebagai Pengawas Minum Obat (PMO) dengan Tingkat Keberhasilan Pengobatan Penderita Tuberkulosis Paru. Jurnal Keperawatan Unsyiah Pascasarjana Magister Universitas Syiah Kuala.

9. Notoatmodjo, S. 2010. IImu Perilaku Kesehatan. Jakarta. Rieneka Cipta.

10. Hayati, D., Musa, E. 2016. Hubungan Kinerja Pengawas Menelan Obat dengan Kesembuhan Tuberkulosis di UPT Puskesmas Arcamanik Kota Bandung. Jurnal Ilmu Keperawatan Universitas BSI Bandung 